\title{
Effects of ketamine on neurogenesis, extracellular matrix homeostasis and proliferation in hypoxia-exposed HT22 murine hippocampal neurons
}

\author{
THOMAS PICHL, TITUS KELLER, CHRISTOPH HÜNSELER, BERNHARD ROTH, \\ RUTH JANOSCHEK, SARAH APPEL and EVA HUCKLENBRUCH-ROTHER \\ Department of Pediatrics and Adolescent Medicine, University of Cologne, \\ Faculty of Medicine and University Hospital, D-50931 Cologne, Germany
}

Received January 21, 2020; Accepted May 14, 2020

DOI: $10.3892 /$ br.2020.1330

\begin{abstract}
Ketamine is a widely used drug in pediatric anesthesia, and both neurotoxic and neuroprotective effects have been associated with its use. There are only a few studies to date which have examined the effects of ketamine on neurons under hypoxic conditions, which may lead to severe brain damage and poor neurocognitive outcomes in neonates. In the present study, the effects of ketamine on cellular pathways associated with neurogenesis, extracellular matrix homeostasis and proliferation were examined in vitro in hypoxia-exposed neurons. Differentiated HT22 murine hippocampal neurons were treated with 1, 10 and $20 \mu \mathrm{M}$ ketamine and cultured under hypoxic or normoxic conditions for $24 \mathrm{~h}$ followed by quantitative PCR analysis of relevant candidate genes. Ketamine treatment did not exert any notable effects on the mRNA expression levels of markers of neurogenesis (neuronal growth factor and syndecan 1), extracellular matrix homeostasis (matrix-metalloproteinase 2 and 9, tenascin $C$ and tenascin $\mathrm{R}$ ) or proliferation markers (Ki67 and proliferating cell nuclear antigen) compared with the respective untreated controls. However, there was a tendency towards downregulation of multiple cellular markers under hypoxic conditions and simultaneous ketamine treatment. No dose-dependent association was found in the ketamine treated groups for genetic markers of neurogenesis, extracellular matrix homeostasis or proliferation. Based on the results, ketamine may have increased the vulnerability of hippocampal neurons in vitro to hypoxia, independent of the dose. The results of the present study contribute to the ongoing discussion on the safety concerns around ketamine use in pediatric clinical practice from a laboratory perspective.
\end{abstract}

Correspondence to: Dr Thomas Pichl, Department of Pediatrics and Adolescent Medicine, University of Cologne, Faculty of Medicine and University Hospital, Gebaeude 44a, Forschungspavillon, 16 Robert-Koch Street, D-50931 Cologne, Germany

E-mail: thomas.pichl@nhs.net

Key words: cell line, cell proliferation, extracellular matrix, hypoxia, ketamine, neurogenesis

\section{Introduction}

Ketamine has been used clinically for $>40$ years (1). By disconnecting thalamic and limbic brain functions through antagonism of the NMDAR, ketamine induces dissociative anesthesia while preserving spontaneous respiration and cardiovascular stability $(2,3)$. With a low risk profile for severe adverse effects, ketamine is widely used in pediatric anesthesia $(4,5)$. However, the potential neurotoxic effects of ketamine on the developing brain have raised concern amongst healthcare professionals for $>20$ years $(6,7)$. Numerous animal studies have reported apoptotic neurodegeneration and impaired neurological outcomes due to ketamine treatment, casting doubt on the safety of ketamine use in neonatal and pediatric patients (7-15). Ikonomidou et al (7) showed that exposure to ketamine resulted in widespread neuronal apoptosis in rat pups. These findings were supported by subsequent studies on developing rat brains, which linked ketamine exposure to upregulated expression of NMDA receptor subunits and pro-apoptotic genes and proteins, such as p53 and cleaved caspase-3 (10,12). Similarly, increased expression of NMDA receptors and apoptosis was observed in the frontal cortex of ketamine-treated perinatal rhesus monkeys (8). Furthermore, rhesus monkeys underperformed in cognitive behavior tests for several years following exposure to ketamine early in life (9).

In contrast to these findings, neuroprotective effects of ketamine on the developing brain have also been demonstrated. Anand et al (16) reported that ketamine may ameliorate pain-induced neurotoxicity in newborn rats, likely, but not solely through the inhibition of inflammatory pathways $(6,16)$.

Perinatal hypoxia-ischemia may lead to a variety of types of severe brain damage in term and preterm neonates, such as hypoxic-ischemic encephalopathy and periventricular leukomalacia $(17,18)$. Several in vitro and in vivo studies have provided evidence of the neuroprotective effects of ketamine under hypoxic conditions (19-21). In 1987, Rothman et al (19) showed that ketamine attenuated the neurotoxic effects of hypoxia on hippocampal neurons in vitro. NMDA receptor antagonism is 
considered a key factor in the protection of neurons and glial cells from glutamate-induced excitotoxicity, providing improved outcomes in hypoxic-ischemic rat pups $(22,23)$. Chang et al (21) showed that ketamine ameliorated the inflammatory response due to hypoxia in the cortex of fetal sheep via a Toll-like receptor mediated pathway. To the best of our knowledge, there are no studies published to date on the interaction between ketamine and hypoxia in primates. Similarly, there are no prospective studies examining the safety of ketamine in paediatric patients to the best of our knowledge; however, retrospective studies on the use of ketamine and other anesthetic drugs in childhood have not found convincing evidence of an association with impaired neurocognitive function in later life $(24,25)$.

In summary, there is conflicting evidence regarding the neurotoxic and neuroprotective effects of ketamine on the developing brain. Ketamine has been shown to protect neurons and glial cells by attenuating glutamate-induced excitotoxicity and inhibiting an inflammatory response (19-21,26). However, the number of studies available on the relevant neurocellular mechanisms are limited $(14,21,27-30)$, and hypoxia-induced neurotoxicity and potential amelioration through ketamine remains poorly understood.

In the present study, it was hypothesized that ketamine attenuated the neurotoxic effects of hypoxia, and this was assessed by measuring the expression of cellular markers of proliferation, neurogenesis and extracellular matrix homeostasis. The results of the present study may contribute to an improved understanding of how hypoxia-induced neurotoxicity is affected by the presence of ketamine.

In vitro experiments were used as they allow for identification of relevant cellular pathways under standardized and simplified conditions (31). Experiments were performed on HT22 murine hippocampal cells. Studies investigating pathways in the central nervous system often focus on hippocampal formation, which is known to serve a key role in long-term potentiation and memory consolidation, emotional perception as well as endocrinological responses (32-34). An improved understanding of the hippocampal cellular pathways activated under hypoxic conditions and potential alterations due to ketamine is therefore crucial for the development of potential new anesthetic techniques with the aim of reducing the effects of hypoxia-induced brain damage in neonates.

\section{Materials and methods}

Cell culture. Murine hippocampal HT22 cells were generously provided by Professor Axel Methner, Department of Neurology, Düsseldorf University Hospital. Cells were cultured at $37^{\circ} \mathrm{C}$ with $5 \% \mathrm{CO}_{2}$ volume fraction in DMEM, high glucose (Thermo Scientific Fisher, Inc.) supplemented with 10\% FBS (Sigma-Aldrich; Merck KGaA) and 1\% penicillin-streptomycin solution (Sigma-Aldrich; Merck KGaA). A total of $1 \times 10^{5}-1 \times 10^{6}$ HT22 cells were plated in TC Schale 100 cell culture dishes (Sarstedt, Inc.) and cultured for $48 \mathrm{~h}$ in supplemented DMEM.

For differentiation, the cells were treated with Neurobasal ${ }^{\mathrm{TM}}$ medium (Thermo Fisher Scientific, Inc.) for $24 \mathrm{~h}$, supplemented with $1 \% 100 \mathrm{x} \mathrm{N}_{2}$ supplement (Thermo Fisher Scientific, Inc.) and $10 \%$ FBS and $1 \%$ penicillin-streptomycin solution.
Hypoxia and ketamine model. HT22 cells have long been used as a model cell line for examining oxidative glutamate toxicity $(31,35,36)$, but to the best of our knowledge, have not been previously used to study the effects of hypoxia and ketamine treatment on the developing brain.

After $24 \mathrm{~h}$ of differentiation, Neurobasal ${ }^{\mathrm{TM}}$ medium was replaced with supplemented DMEM. Ketamine $(10 \mathrm{mg} / \mathrm{ml}$; Ketamin-Actavis, Injektionslösung, Actavis Group PTC EHF) was added to culture dishes to final ketamine concentrations of 1,10 or $20 \mu \mathrm{M}$. Control cell culture dishes were handled in the same manner, but no ketamine or vehicle was added. Ketamine-incubated HT22 cells and controls were cultured for $24 \mathrm{~h}$ either under hypoxic $\left(1 \% \mathrm{O}_{2}, 5 \% \mathrm{CO}_{2}\right)$ or normoxic $\left(21 \% \mathrm{O}_{2}, 5 \% \mathrm{CO}_{2}\right)$ conditions. Ketamine doses of 1,10 or $20 \mu \mathrm{M}$ (equivalent to $0.238,2.38$ or $5.76 \mu \mathrm{g} / \mathrm{ml}$, respectively, in culture medium) were chosen in accordance with in vivo measurements of brain and plasma ketamine concentration as reported by Liu et al (10).

Reverse transcription-quantitative (q)PCR. mRNA was isolated from harvested HT22 cells using TriReagent ${ }^{\circledR}$ RNA Isolation Reagent (Sigma-Aldrich; Merck KGaA) according to the manufacturer's protocol. mRNA concentrations were measured using a Nano Quant infinite M200 Pro (Tecan Group, Ltd.). Moloney Murine Leukemia Virus Reverse Transcriptase was used to synthesize first strand cDNA according to the manufacturer's protocol (Promega Corporation).

For TaqMan ${ }^{\mathrm{TM}}$ qPCR (7500 Real-Time PCR system, Applied Biosystems; Thermo Fisher Scientific, Inc.), $0.5 \mu 1$ each of the forward and reverse primers, and the probe (all purchased from Eurofins Genomics), $2.5 \mu \mathrm{l}$ cDNA template and $12.5 \mu 1$ Platinum $^{\mathrm{TM}}$ Quantitative PCR SuperMix-UDG (Thermo Fisher Scientific, Inc.) were added per well in a 96-well plate and amplified for 40 cycles (annealing temperature, $60^{\circ} \mathrm{C}$ ) according to the manufacturer's protocol. The sequences of the primers used and the respective probes are presented in Table SI. qPCR data of mRNA expression levels were normalized using the $2^{-\Delta \Delta C q}$ method in Microsoft Excel 2010 (Microsoft Corporation) using GAPDH as the reference gene (37).

Statistical analysis. To evaluate the effects of ketamine treatment, comparisons between multiple groups were performed using a Kruskal-Wallis one-way ANOVA with a post-hoc Dunn's test. All statistical tests were performed using GraphPad Prism version 8 (GraphPad Software, Inc.). Results are presented as the means of mRNA expression. Error bars represent the standard deviations.

\section{Results}

The aim of the present study was to improve our understanding of the effects of ketamine on developing neurons under hypoxic conditions. Differentiated murine HT22 cells were incubated with different concentrations of ketamine $(1,10$ or $20 \mu \mathrm{M})$ for $24 \mathrm{~h}$ under hypoxic or normoxic conditions. qPCR analysis of cellular markers associated with neurogenesis, proliferation and extracellular matrix homeostasis was performed to determine the effects of ketamine. 
$m R N A$ expression levels of $N G F$. To investigate how the mRNA expression levels of $N G F$, an important neurotrophin for migration and maturation of neurons in the developing brain (38), were affected by hypoxia and ketamine treatment, the mRNA expression levels of $N G F$ in differentiated HT22 cells were determined after $24 \mathrm{~h}$ of treatment with various ketamine concentrations under hypoxic and normoxic conditions.

There was no evidence of differences in the mRNA expression levels of $N G F$ following ketamine treatment compared with the hypoxic and normoxic control groups $(\mathrm{P}>0.99$ for all comparisons). However, there was a decrease in $N G F$ expression levels in cells cultured under hypoxic conditions compared with the normoxic cultured cells treated with the same concentration of ketamine to $16 \%(\mathrm{~K} 1 ; \mathrm{P}=0.25), 17 \%$ $(\mathrm{K} 10 ; \mathrm{P}=0.38)$ and $13 \%(\mathrm{~K} 20 ; \mathrm{P}=0.19)$. All mRNA expression levels stated are relative to the expression levels in the control (Co NO) group. There was no evidence of differences in the mRNA expression levels in hypoxic and normoxic cultured cells in the control groups ( $\mathrm{P}>0.99$; Fig. 1).

$m R N A$ expression levels of $S d c 1$. To investigate how the mRNA expression levels of $S d c l$, which is expressed by neuronal progenitor cells (39), were affected by hypoxia and ketamine treatment, the mRNA expression levels of $S d c l$ in differentiated HT22 cells after $24 \mathrm{~h}$ of treatment with various ketamine concentrations were determined under hypoxic and normoxic conditions.

There was no evidence of differences in the mRNA expression levels of $S d c 1$ following ketamine treatment compared with the hypoxic and normoxic control groups $(\mathrm{P}>0.99$ for all comparisons). However, there was a decrease in the expression levels in cells cultured under hypoxic conditions respectively compared with the normoxic cultured cells treated with the same concentration of ketamine to $24 \%(\mathrm{~K} 10 ; \mathrm{P}=0.11)$ and $28 \%$ (K20; $\mathrm{P}=0.41$ ). All mRNA expression levels stated are relative to the expression levels in the Co NO. There was no evidence of a difference in mRNA expression levels between hypoxia and normoxia for $\mathrm{K} 1(\mathrm{P}>0.99)$ or in the control groups (P>0.99; Fig. 1).

mRNA expression levels of PCNA. To investigate how the mRNA expression levels of PCNA, a widely used proliferation marker $(40,41)$, were affected by hypoxia and ketamine treatment, the mRNA expression levels of PCNA were determined in the differentiated HT22 cells after $24 \mathrm{~h}$ of treatment with various concentrations of ketamine under hypoxic and normoxic conditions.

There was no evidence of differences in the mRNA expression levels of PCNA following ketamine treatment compared with the hypoxic and normoxic control groups ( $\mathrm{P}>0.99$ for all comparisons). However, there was a downregulation of PCNA expression in cells cultured under hypoxic conditions respectively compared with normoxic cultured cells treated with the same concentration of ketamine to $7 \%(\mathrm{~K} 1 ; \mathrm{P}=0.09)$, $11 \%(\mathrm{~K} 10 ; \mathrm{P}=0.35)$ and $8 \%(\mathrm{~K} 20 ; \mathrm{P}=0.25)$. All mRNA expression levels stated are relative to the expression levels in the $\mathrm{Co}$ NO group. There was no evidence of a difference in mRNA expression levels between hypoxic and normoxic cultured cells in the control groups ( $>0.99$; Fig. 2). $m R N A$ expression levels of Ki67. To investigate how the mRNA expression of Ki67, which is expressed in all phases of the cell cycle of proliferating cells (42), was affected by hypoxia and ketamine treatment, the mRNA expression levels of Ki67 were determined in the differentiated HT22 cells after $24 \mathrm{~h}$ of treatment with various concentrations of ketamine under hypoxic and normoxic conditions.

There was no evidence of a difference in the mRNA expression levels of Ki67 following treatment with ketamine compared with the hypoxic and normoxic control groups ( $\mathrm{P}>0.99$ for all comparisons). However, there was a downregulation in the Ki67 expression levels cultured under hypoxic conditions respectively compared with the normoxic cultured cells treated with the same concentration of ketamine to $9 \%$ $(\mathrm{K} 1 ; \mathrm{P}=0.04)$ and $11 \%(\mathrm{~K} 20 ; \mathrm{P}=0.27)$. All mRNA expression levels stated are relative to the expression levels in the Co NO group. There was no evidence of a difference in the mRNA expression levels between the hypoxic and normoxic cultured cells in $\mathrm{K} 10$ ( $\mathrm{P}=0.63)$ or in the control group ( $\mathrm{P}>0.99$; Fig. 2).

mRNA expression levels of MMP2. To investigate how the mRNA expression levels of $M M P 2$, an enzyme in the MMP group of proteins which serve important roles in the proteolysis of the extracellular matrix following brain injury (43), were affected by hypoxia and ketamine exposure, the mRNA expression levels of MMP2 in differentiated HT22 cells after $24 \mathrm{~h}$ of treatment with various concentrations of ketamine were determined under hypoxic and normoxic conditions. There was no evidence of differences in the mRNA expression levels of $M M P 2$ following ketamine treatment or hypoxia ( $\mathrm{P}>0.99$ for all between-group comparisons) (Fig. 3).

mRNA expression levels of MMP9. To investigate how the mRNA expression levels of $M M P 9$ were affected by hypoxia and ketamine exposure, the mRNA expression levels of $M M P 9$ in differentiated HT22 cells were determined after $24 \mathrm{~h}$ of treatment with various concentrations of ketamine under hypoxic and normoxic conditions.

There was no evidence of differences in the mRNA expression of $M M P 9$ following ketamine treatment compared with the hypoxic and normoxic control groups $(\mathrm{P}>0.99$ for all comparisons). However, there was a downregulation of $M M P 9$ expression in cells cultured under hypoxic conditions respectively compared with the normoxic cultured cells treated with the same concentration of ketamine to $28 \%(\mathrm{~K} 1 ; \mathrm{P}=0.42)$ and $30 \%$ (K10; $\mathrm{P}=0.23)$. All mRNA expression levels stated are relative to the expression levels in the Co NO group. There was no significant difference between hypoxia and normoxia for $\mathrm{K} 20(\mathrm{P}>0.99)$ or in the control groups $(\mathrm{P}>0.99$; Fig. 3$)$.

mRNA expression levels of TenC. To investigate how the mRNA expression of TenC, which is an extracellular matrix protein expressed following tissue injury (44), was affected by hypoxia and ketamine exposure, the mRNA expression levels of TenC in differentiated HT22 cells were determined after $24 \mathrm{~h}$ of treatment with various concentrations of ketamine under hypoxic and normoxic conditions.

There was no evidence of differences in the mRNA expression of TenC following ketamine treatment or hypoxia ( $\mathrm{P}>0.99$ for all between-group comparisons) (Fig. 4). 
NGF $24 \mathrm{~h}$

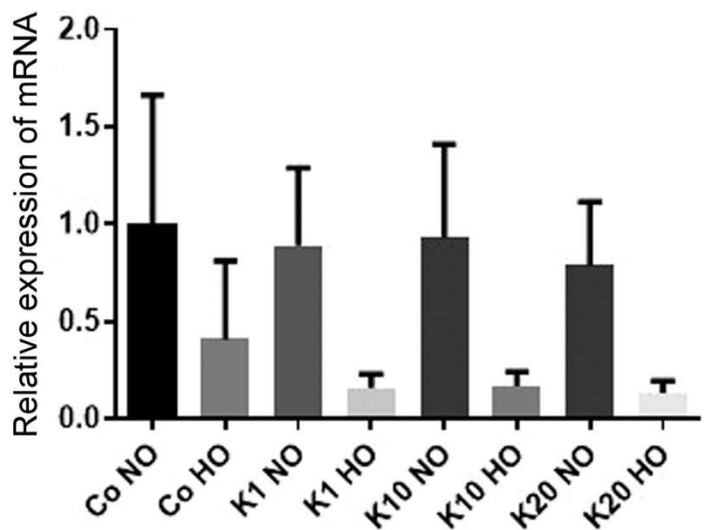

Sdc1 $24 \mathrm{~h}$

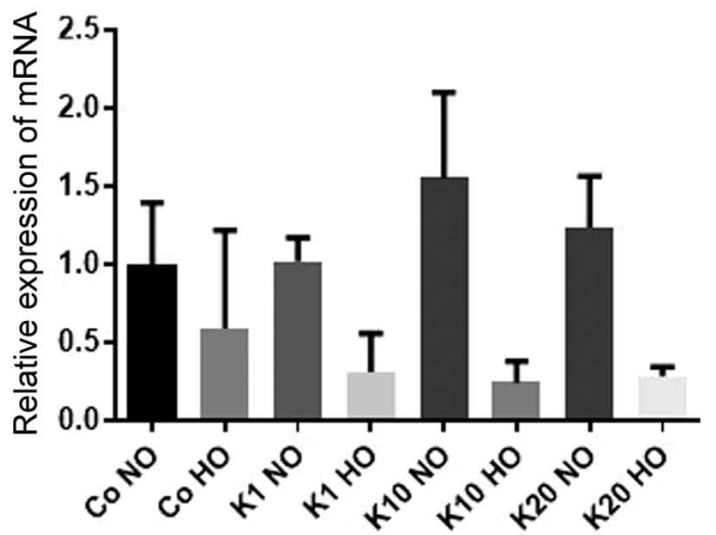

Figure 1. Relative mRNA expression levels of the neurogenesis markers $N G F$ and $S d c 1$ in differentiated HT22 cells after 24 h of culture under HO or NO conditions. Cells were incubated with various concentrations of ketamine hydrochloride. Results are presented as the mean \pm standard deviation of at least three experimental repeats. $N G F$, nerve growth factor; Sdc, syndecan 1, HO, hypoxic; NO, normoxic; CO, control; K1, $1 \mu \mathrm{M}$ ketamine hydrochloride; K10, $10 \mu \mathrm{M}$ ketamine hydrochloride; $\mathrm{K} 20,20 \mu \mathrm{M}$ ketamine hydrochloride.

PCNA $24 \mathrm{~h}$

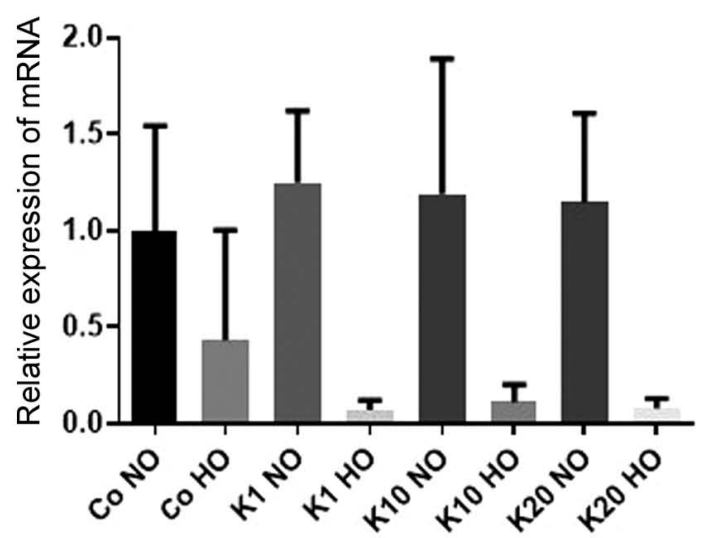

KI67 $24 \mathrm{~h}$

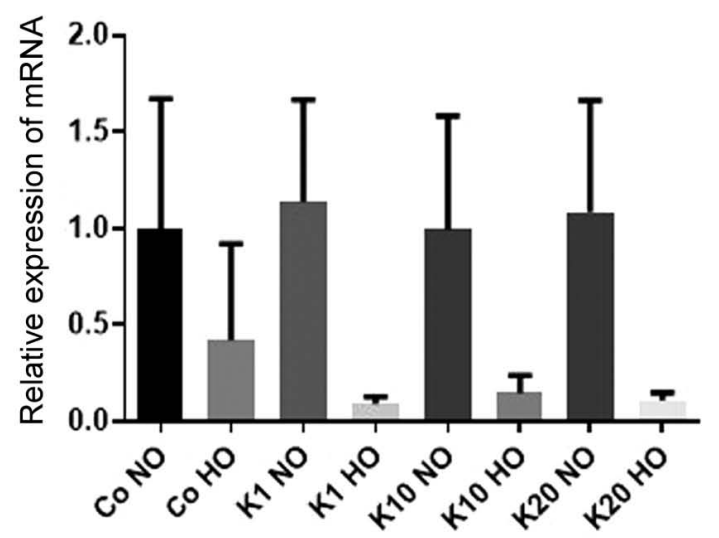

Figure 2. Relative mRNA expression levels of the proliferation markers PCNA and Ki67 in differentiated HT22 cells after 24 h of culture under HO or NO conditions. Cells were incubated with various concentrations of ketamine hydrochloride. Results are presented as the mean \pm standard deviation of at least three experimental repeats. PCNA, proliferating cell nuclear antigen; HO, hypoxic; NO, normoxic; CO, control; K1, $1 \mu \mathrm{M}$ ketamine hydrochloride; K10, $10 \mu \mathrm{M}$ ketamine hydrochloride; K20, $20 \mu \mathrm{M}$ ketamine hydrochloride.

$m R N A$ expression levels of TenR. To investigate how the mRNA expression of TenR, an extracellular matrix protein exclusively expressed in the nervous system (45), was affected by hypoxia and ketamine exposure, the mRNA expression levels of TenR in differentiated HT22 cells were determined after $24 \mathrm{~h}$ of treatment with various concentrations of ketamine under hypoxic and normoxic conditions.

There was no evidence of differences in the mRNA expression levels of TenR following ketamine treatment compared with the hypoxic and normoxic control groups. However, there was a downregulation in the expression of TenR in cells cultured under hypoxic conditions respectively compared with the normoxic cultured cells treated with the same concentration of ketamine to $12 \%(\mathrm{~K} 1, \mathrm{P}=0.14)$ and $15 \%(\mathrm{~K} 10, \mathrm{P}=0.25)$. All mRNA expression levels stated are relative to the expression levels in the Co NO group. There was no significant difference in the expression of TenR between cells grown under hypoxic and normoxic conditions for K20 $(\mathrm{P}=0.89)$ or between the normoxic and hypoxic controls groups ( $\mathrm{P}>0.99$; (Fig. 4).

\section{Discussion}

The aim of the present study was to investigate the effects of ketamine on the expression of markers involved in cellular pathways associated with proliferation, neurogenesis and extracellular matrix homeostasis in hypoxia-exposed neurons.

The results showed that ketamine treatment alone in HT22 cells did not significantly affect the expression of the assessed markers of proliferation, neurogenesis or extracellular matrix homeostasis compared with their respective untreated controls. Furthermore, untreated control groups did not exhibit any significant differences in expression of the markers assessed when compared with hypoxia cultured cells.

However, there was a tendency towards downregulation of markers of proliferation, neurogenesis and, to a lesser extent, extracellular matrix homeostasis under hypoxic conditions combined with ketamine treatment compared with their respective normoxic control group. No dose-dependent association was observed among the ketamine treated groups. 
MMP2 $24 \mathrm{~h}$

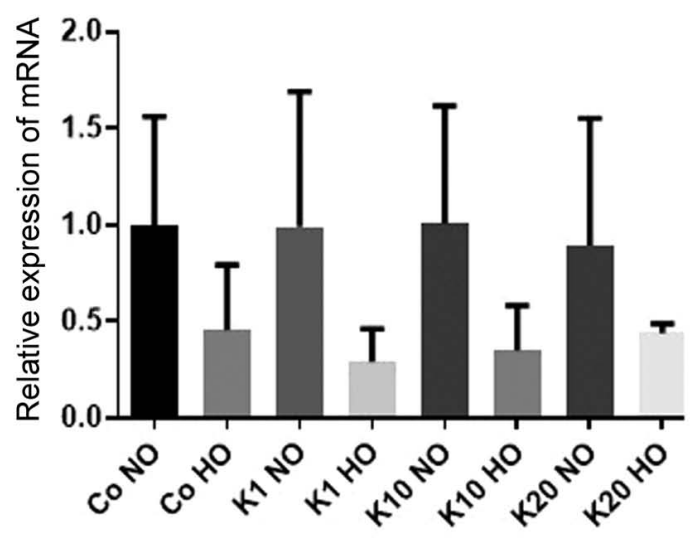

MMP9 $24 \mathrm{~h}$

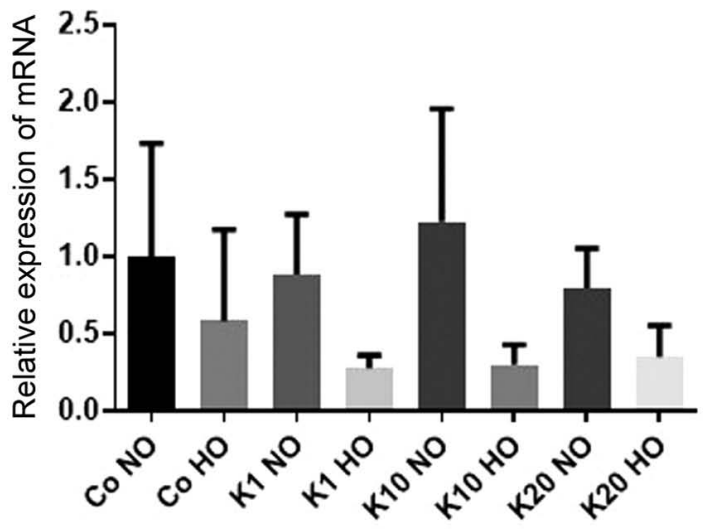

Figure 3. Relative mRNA expression levels of markers of extracellular matrix homeostasis, $M M P 9$ and $M M P 9$ in differentiated HT22 cells after 24 h of culture under $\mathrm{HO}$ or NO conditions. Cells were incubated with various concentrations of ketamine hydrochloride. Results are presented as the mean \pm standard deviation of at least three experimental repeats. $M M P$, matrix metalloproteinase; $\mathrm{HO}$, hypoxic; $\mathrm{NO}$, normoxic; CO, control; K1, $1 \mu \mathrm{M}$ ketamine hydrochloride; $\mathrm{K} 10,10 \mu \mathrm{M}$ ketamine hydrochloride; K20, $20 \mu \mathrm{M}$ ketamine hydrochloride.

Tenc $24 \mathrm{~h}$

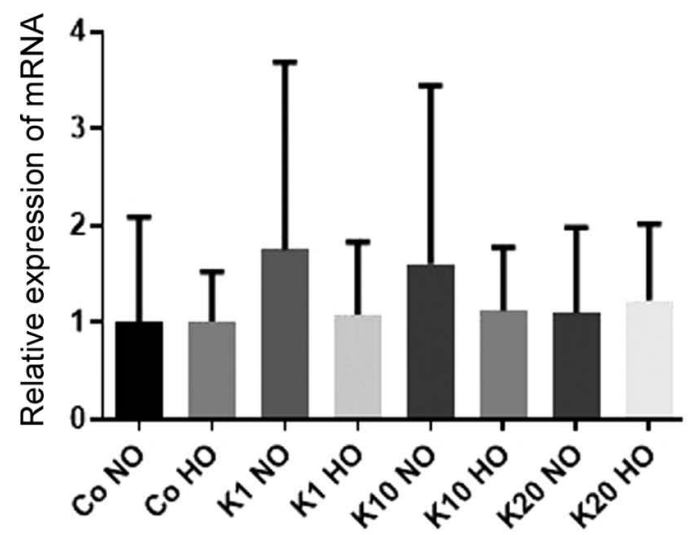

TenR $24 \mathrm{~h}$

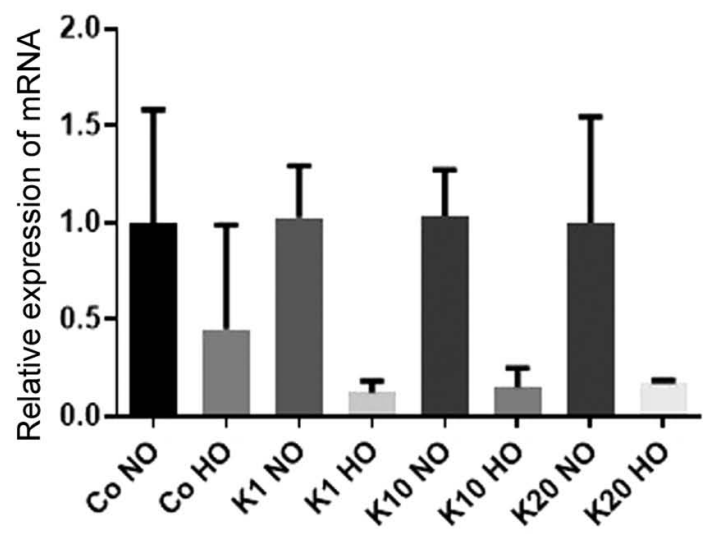

Figure 4. Relative mRNA expression levels of markers of extracellular matrix homeostasis, TenC and TenR in differentiated HT22 cells after 24 h of culture under $\mathrm{HO}$ or NO conditions. Cells were incubated with various concentrations of ketamine hydrochloride. Results are presented as the mean \pm standard deviation of at least three experimental repeats. TenC, tenascin $C$; TenR, tenascin $R$; HO, hypoxic; NO, normoxic; CO, control; K1, $1 \mu \mathrm{M}$ ketamine hydrochloride; $\mathrm{K} 10,10 \mu \mathrm{M}$ ketamine hydrochloride; K20, $20 \mu \mathrm{M}$ ketamine hydrochloride.

Taken together, these results suggest increased vulnerability of hippocampal neurons in vitro to hypoxia in the presence of ketamine, independent of the dose of ketamine.

Several tested markers allow for specific interpretations. $S d c l$ is a transmembrane heparan sulfate proteoglycan that is found in abundance in mammalian brains prior to neurogenesis (39). $N G F$ stimulates migration and maturation of neurons in the developing brain and has neuroprotective functions in the adult brain (38). Ki67 and PCNA are expressed by replicating cells only and are widely used as markers to evaluate cellular proliferation $(40,42)$. Thus, ketamine treatment may not be neurotoxic itself but may aggravate the effects of hypoxia, which thus results in an earlier onset of neurotoxic effects in the ketamine-treated groups compared with the untreated control groups. This would support findings from previous studies which demonstrated the potential neurotoxicity of ketamine treatment (7-15).

The results of expression of markers of extracellular matrix homeostasis were less conclusive. Only MMP-9 and TenR exhibited a similar pattern to that described above; whereas there was no evidence of differences in the expression of MMP2 and TenC. Although not significant, $M M P 2$ mRNA expression levels still exhibited a tendency similar to that of MMP9. The downregulation in $M M P 2$ and $M M P 9$ expression under hypoxic conditions is a potentially interesting find, as matrix-metalloproteinases degrade the extracellular matrix, activate TNF- $\alpha$ and their expression is known to be elevated in cerebral ischemia $(43,46)$. However, $M M P s$ are also known for their dual involvement in cellular processes of early tissue damage and late tissue repair during brain injury (47). Future studies investigating the mRNA expression patterns of MMPs following hypoxia exposure for various time periods may provide an improved understanding of this complex matter.

A possible explanation for the observations of the present study lies in the limitation of the cell culture model. Zhao et al (31) showed that HT22 cells differentiated using $\mathrm{N}_{2}$ supplement expressed NMDA receptors which were not 
expressed by undifferentiated HT22 cells. It is possible that the HT22 cells may have returned to their undifferentiated state as a result of prolonged exposure to hypoxia with a subsequent downregulation of all the examined genes. However, the fact that no significant effects of hypoxia alone were detected in the untreated groups suggests the possibility of a specific ketamine-dependent effect in the present study.

Ketamine concentrations of 1,10 and $20 \mu \mathrm{M}$ were chosen based on a previous study (10). As neurotoxicity due to ketamine was only observed when cells were treated with high doses in various studies $(8,10,13)$, the ketamine concentrations used in the present study were likely too low to produce a direct neurotoxic effect.

Several previous studies have demonstrated the significant effects of ketamine treatment on neuronal tissue when the drug is applied as a bolus $(6,10,13-15)$. In the present study, hippocampal cells were incubated for $24 \mathrm{~h}$ to simulate extended ketamine treatment in neonates, which may partly explain the inconsistencies in the data when compared with previous studies. There are certain studies showing significant ketamine neurotoxicity following continuous infusion $(8,9,21)$, thus further investigation that directly compares the effects of short and long term treatment is required to elucidate the effects of the length of treatment with ketamine on neurotoxicity.

Although there are several studies demonstrating the potential neurotoxic and neuroapoptotic effects of ketamine (7-15), comparatively less research has been performed on its effects in hypoxic conditions. Animal studies showed that NMDA receptor blockade and ketamine treatment may result in neuroprotective outcomes in hypoxia $(20,22,23)$. However, Ulbrich et al (48) did not observe any significant effects of ketamine incubation in a study performed on a SH-SY5Y neuronal cell line. The latter is consistent with the results of the present study and is in contrast to the findings of Rothman et al (19), who described preserved action potentials and higher ATP levels in hypoxic primary hippocampal neurons when treated with ketamine. Similarly, ketamine ameliorated the neuroinflammatory response to transient hypoxia in fetal sheep (21). A possible explanation for these contradictory findings is that previously described neuroprotective findings may not be directly caused by the effects of ketamine on neurons, but rather through more complex interactions between the drug and its metabolites, glial cells and neurons. Glial cells are naturally present in animal studies and in primary neuronal cell cultures, but not in immortalized cell lines consisting of a sole cell type such as HT22 or SH-SY5Y (49). This supports the previously suggested hypothesis of glial cells serving a key role in neuroprotection following acute brain injury (50-52). Furthermore, ketamine is metabolized in complex pathways in vitro, which results in the circulation of various ketamine metabolites (53). This may be crucial regarding the neurotoxic and neuroprotective ketamine effects described in animal studies and will be omitted by default in a cell culture model.

Another limitation of the present study is that the experiments were performed on a single cell line only. Further studies, particularly animal and primary cell culture models are required to obtain a more definite answer regarding the potential aggravation of hypoxia-induced damage due to ketamine treatment.

The present study is a modest contribution to the ongoing discussion of the potential neurotoxic and neuroprotective effects of the commonly used anesthetic and analgesic pediatric drug ketamine. Overall, the data obtained from the present study are not conclusive and thus should not be used in clinical decision making. However, the findings do broaden our understanding of neuronal gene expression in hypoxia and may thus serve as a starting point for future investigations.

In conclusion, the results of the present study suggest potential aggravation of hypoxia-induced neurotoxicity in hippocampal neurons in the presence of ketamine, as observed in the patterns of downregulation of genetic markers of proliferation, neurogenesis and extracellular matrix homeostasis. However, there was no dose-response association for ketamine treatment observed, which may be due to the ketamine concentrations used and the limitations of the cell culture model used.

\section{Acknowledgements}

We would like to thank Professor Axel Methner at the Johannes Gutenberg University Mainz for providing us with the HT22 cell line. Furthermore, we would like to thank Miss Christina Vohlen, Miss Maria Wohlfarth and Mr. Gregor Fink (Department of Pediatrics and Adolescent Medicine, University of Cologne) for their excellent technical assistance.

\section{Funding}

This study was supported by a Köln Fortune grant (grant no. 69/2010).

\section{Availability of data and materials}

The datasets used and/or analyzed during the present study are available from the corresponding author on reasonable request.

\section{Authors' contributions}

$\mathrm{BR}, \mathrm{CH}, \mathrm{TK}$ and EH-R. participated in the design of the study. Molecular analyses and cell culture experiments were performed by TP and SA. TP, SA, RJ and EH-R. analyzed and interpreted the data. TP and EH-R drafted and revised the manuscript. All authors read and approved the final manuscript.

\section{Ethics approval and consent to participate}

Not applicable.

\section{Patient consent for publication}

Not applicable.

\section{Competing interests}

The authors declare that they have no competing interests. 


\section{References}

1. Domino EF: Taming the ketamine tiger. Anesthesiology 113 678-686, 2010.

2. Arora S: Combining ketamine and propofol ('ketofol') for emergency department procedural sedation and analgesia: A review. West J Emerg Med 9: 20-23, 2008.

3. Green SM, Roback MG, Kennedy RM and Krauss B: Clinical practice guideline for emergency department ketamine dissociative sedation: 2011 update. Ann Emerg Med 57: 449-461, 2011.

4. Green SM, Roback MG, Krauss B, Brown L, McGlone RG, Agrawal D, McKee M, Weiss M, Pitetti RD, Hostetler MA, et al: Predictors of emesis and recovery agitation with emergency department ketamine sedation: An individual-patient data meta-analysis of 8,282 children. Ann Emerg Med 54: 171-180.e4, 2009.

5. Street MH and Gerard JM: A fixed-dose ketamine protocol for adolescent sedations in a pediatric emergency department. J Pediatr 165: 453-458, 2014.

6. Yan J and Jiang H: Dual effects of ketamine: Neurotoxicity versus neuroprotection in anesthesia for the developing brain J Neurosurg Anesthesiol 26: 155-160, 2014.

7. Ikonomidou C, Bosch F, Miksa M, Bittigau P, Vöckler J, Dikranian K, Tenkova TI, Stefovska V, Turski L and Olney JW: Blockade of NMDA receptors and apoptotic neurodegeneration in the developing brain. Science 283: 70-74, 1999.

8. Slikker W Jr, Zou X, Hotchkiss CE, Divine RL, Sadovova N, Twaddle NC, Doerge DR, Scallet AC, Patterson TA, Hanig JP, et al: Ketamine-induced neuronal cell death in the perinatal rhesus monkey. Toxicol Sci 98: 145-158, 2007.

9. Paule MG, Li M, Allen RR, Liu F, Zou X, Hotchkiss C, Hanig JP, Patterson TA, Slikker W Jr and Wang C: Ketamine anesthesia during the first week of life can cause long-lasting cognitive deficits in rhesus monkeys. Neurotoxicol Teratol 33: 220-230, 2011.

10. Liu F, Paule MG, Ali S and Wang C: Ketamine-induced neurotoxicity and changes in gene expression in the developing rat brain. Curr Neuropharmacol 9: 256-261, 2011.

11. Ye Z, Li Q, Guo Q, Xiong Y, Guo D, Yang H and Shu Y: Ketamine induces hippocampal apoptosis through a mechanism associated with the caspase-1 dependent pyroptosis Neuropharmacology 128: 63-75, 2018.

12. Yan J, Huang Y, Lu Y, Chen J and Jiang H: Repeated administration of ketamine can induce hippocampal neurodegeneration and long-term cognitive impairment via the ROS/HIF-1 $\alpha$ pathway in developing rats. Cell Physiol Biochem 33: 1715-1732, 2014

13. Huang L, Liu Y, Jin W, Ji X and Dong Z: Ketamine potentiates hippocampal neurodegeneration and persistent learning and memory impairment through the PKC $\gamma$-ERK signaling pathway in the developing brain. Brain Res 1476: 164-171, 2012.

14. Hayashi H, Dikkes P and Soriano S: Repeated administration of ketamine may lead to neuronal degeneration in the developing rat brain. Pediatr Anesth 12: 770-774, 2002.

15. Zou X, Patterson TA, Sadovova N, Twaddle NC, Doerge DR, Zhang X, Fu X, Hanig JP, Paule MG, Slikker W and Wang C: Potential neurotoxicity of ketamine in the developing rat brain. Toxicol Sci 108: 149-158, 2009.

16. Anand KJ, Garg S, Rovnaghi CR, Narsinghani U, Bhutta AT and Hall RW: Ketamine reduces the cell death following inflammatory pain in newborn rat brain. Pediatr Res 62: 283-290, 2007.

17. Khwaja $\mathrm{O}$ and Volpe JJ: Pathogenesis of cerebral white matter injury of prematurity. Arch Dis Child Fetal Neonatal Ed 93: F153-F161, 2008.

18. Douglas-Escobar M and Weiss MD: Hypoxic-ischemic encephalopathy. JAMA Pediatr 169: 397-403, 2015

19. Rothman SM, Thurston JH, Hauhart RE, Clark GD and Solomon JS: Ketamine protects hippocampal neurons from anoxia in vitro. Neuroscience 21: 673-678, 1987

20. Spandou E, Karkavelas G, Soubasi V, Avgovstides-Savvopoulou P, Loizidis $\mathrm{T}$ and Guiba-Tziampiri $\mathrm{O}$ : Effect of ketamine on hypoxic-ischemic brain damage in newborn rats. Brain Res 819 $1-7,1999$

21. Chang EI, Zárate MA, Rabaglino MB, Richards EM, Arndt TJ, Keller-Wood M and Wood CE: Ketamine decreases inflammatory and immune pathways after transient hypoxia in late gestation fetal cerebral cortex. Physiol Rep 4: e12741, 2016.

22. Chen HS, Wang Y, Rayudu P, Edgecomb P, Neill J, Segal M, Lipton SA and Jensen FE: Neuroprotective concentrations of the N-methyl-D-aspartate open-channel blocker memantine are effective without cytoplasmic vacuolation following post-ischemic administration and do not block maze learning or long-term potentiation. Neuroscience 86: 1121-1132, 1998.
23. Manning SM, Talos DM, Zhou C, Selip DB, Park HK, Park CJ, Volpe JJ and Jensen FE: NMDA receptor blockade with memantine attenuates white matter injury in a rat model of periventricular leukomalacia. J Neurosci 28: 6670-6678, 2008.

24. Guerra GG, Robertson CMT, Alton GY, Joffe AR, Cave DA, Dinu IA, Creighton DE, Ross DB and Rebeyka IM; Western Canadian Complex Pediatric Therapies Follow-up Group: Neurodevelopmental outcome following exposure to sedative and analgesic drugs for complex cardiac surgery in infancy. Paediatr Anaesth 21: 932-941, 2011.

25. Hansen TG, Pedersen JK, Henneberg SW, Pedersen DA, Murray JC, Morton NS and Christensen K: Academic performance in adolescence after inguinal hernia repair in infancy: A nationwide cohort study. Anesthesiology 114: 1076-1085, 2011.

26. Loss CM, Córdova SD and De Oliveira DL: Ketamine reduces neuronal degeneration and anxiety levels when administered during early life-induced status epilepticus in rats. Brain Res 1474: 110-117, 2012.

27. Turner CP, Gutierrez S, Liu C, Miller L, Chou J, Finucane B, Carnes A, Kim J, Shing E, Haddad T and Phillips A: Strategies to defeat ketamine-induced neonatal brain injury. Neuroscience 210 : 384-392, 2012.

28. Zhang X, Zhao J, Chang T, Wang Q, Liu W and Gao L: Ketamine exerts neurotoxic effects on the offspring of pregnant rats via the Wnt// $/$-catenin pathway. Environ Sci Pollut Res 27: 305-314, 2020

29. Slikker W Jr, Liu F, Rainosek SW, Patterson TA, Sadovova N, Hanig JP, Paule MG and Wang C: Ketamine-induced toxicity in neurons differentiated from neural stem cells. Mol Neurobiol 52: 959-969, 2015.

30. Jiang S, Li X, Jin W, Duan X, Bo L, Wu J, Zhang R, Wang Y, Kang $\mathrm{R}$ and Huang L: Ketamine-induced neurotoxicity blocked by $\mathrm{N}$-Methyl-D-aspartate is mediated through activation of PKC/ERK pathway in developing hippocampal neurons. Neurosci Lett 673: 122-131, 2018.

31. Zhao Z, Lu R, Zhang B, Shen J, Yang L, Xiao S, Liu J and Suo W: Differentiation of HT22 neurons induces expression of NMDA receptor that mediates homocysteine cytotoxicity. Neurol Res 34: 38-43, 2012.

32. Lathe R: Hormones and the hippocampus. J Endocrinol 169: 205-231, 2001.

33. Neves G, Cooke SF and Bliss TV: Synaptic plasticity, memory and the hippocampus: A neural network approach to causality. Nat Rev Neurosci 9: 65-75, 2008.

34. Femenía T, Gómez-Galán M, Lindskog M and Magara S: Dysfunctional hippocampal activity affects emotion and cognition in mood disorders. Brain Res 1476: 58-70, 2012

35. Lee Y, Park HW, Park SG, Cho S, Myung PK, Park BC and Lee DH: Proteomic analysis of glutamate-induced toxicity in HT22 cells. Proteomics 7: 185-193, 2007.

36. Zhang J, Feng J, Ma D, Wang F, Wang Y, Li C, Wang X, Yin X, Zhang M, Dagda RK and Zhang Y: Neuroprotective mitochondrial remodeling by AKAP121/PKA protects HT22 cell from glutamate-induced oxidative stress. Mol Neurobiol 56: 5586-5607, 2019

37. Livak KJ and Schmittgen TD: Analysis of relative gene expression data using real-time quantitative PCR and the 2(-Delta Delta $\mathrm{C}(\mathrm{T})$ ) method. Methods 25: 402-408, 2001

38. Manni L, Rocco ML, Bianchi P, Soligo M, Guaragna M, Barbaro SP and Aloe L: Nerve growth factor: Basic studies and possible therapeutic applications. Growth Factors 31: 115-122, 2013.

39. Wang Q, Yang L, Alexander C and Temple S: The niche factor syndecan-1 regulates the maintenance and proliferation of neural progenitor cells during mammalian cortical development. PLoS One 7: e42883, 2012

40. Bologna-Molina R, Mosqueda-Taylor A, Molina-Frechero N, Mori-Estevez AD and Sánchez-Acuña G: Comparison of the value of PCNA and Ki-67 as markers of cell proliferation in ameloblastic tumors. Med Oral Patol Oral Cir Bucal 18: e174-e179, 2013.

41. Boehm EM, Gildenberg MS and Washington MT: The many roles of PCNA in eukaryotic DNA replication. Enzymes 39: 231-254, 2016.

42. Juríková M, Danihel L, Polák Š and Varga I: Ki67, PCNA, and MCM proteins: Markers of proliferation in the diagnosis of breast cancer. Acta Histochem 118: 544-552, 2016

43. Leonardo CC, Eakin AK, Ajmo JM, Collier LA, Pennypacker KR, Strongin AY and Gottschall PE: Delayed administration of a matrix metalloproteinase inhibitor limits progressive brain injury after hypoxia-ischemia in the neonatal rat. J Neuroinflammation 5: 34, 2008. 
44. Midwood KS, Hussenet T, Langlois B and Orend G: Advances in tenascin-C biology. Cell Mol Life Sci 68: 3175-3199, 2011.

45. Anlar B and Gunel-Ozcan A: Tenascin-R: Role in the central nervous system. Int J Biochem Cell Biol 44: 1385-1389, 2012

46. Cunningham LA, Wetzel M and Rosenberg GA: Multiple roles for MMPs and TIMPs in cerebral ischemia. Glia 50: 329-339, 2005

47. Yang Y and Rosenberg GA: Matrix metalloproteinases as therapeutic targets for stroke. Brain Res 1623: 30-38, 2015.

48. Ulbrich F, Eisert L, Buerkle H, Goebel U and Schallner N: Propofol, but not ketamine or midazolam, exerts neuroprotection after ischaemic injury by inhibition of Toll-like receptor 4 and nuclear factor kappa-light-chain-enhancer of activated B-cell signalling: A combined in vitro and animal study. Eur J Anaesthesiol 33: 670-680, 2016.

49. Gordon J, Amini S and White MK: General overview of neuronal cell culture. Methods Mol Biol 1078: 1-8, 2013.

50. Huang R, Sochocka E and Hertz L: Cell culture studies of the role of elevated extracellular glutamate and $\mathrm{K}+$ in neuronal cell death during and after anoxia/ischemia. Neurosci Biobehav Rev 21: 129-134, 1997.
51. Montero M, González B and Zimmer J: Immunotoxic depletion of microglia in mouse hippocampal slice cultures enhances ischemia-like neurodegeneration. Brain Res 1291: 140-152, 2009.

52. Neumann J, Gunzer M, Gutzeit HO, Ullrich O, Reymann KG and Dinkel K: Microglia provide neuroprotection after ischemia. FASEB J 20: 714-716, 2006.

53. Zanos P, Moaddel R, Morris PJ, Riggs LM, Highland JN Georgiou P, Pereira EFR, Albuquerque EX, Thomas CJ, Zarate CA Jr and Gould TD: Ketamine and ketamine metabolite pharmacology: Insights into therapeutic mechanisms. Pharmacol Rev 70: 621-660, 2018.

This work is licensed under a Creative Commons Attribution-NonCommercial-NoDerivatives 4.0 International (CC BY-NC-ND 4.0) License. 